\title{
Antenatal Depression in East Asia: A Review of the Literature
}

\author{
David Beck Schatz, Mei-Chun Hsiao ${ }^{\bowtie}$ and Chia-Yih Liu \\ Department of Psychiatry, Chang-Gung Memorial Hospital and University, Taoyuan, Taiwan
}

This current study's goal is to summarize the literature regarding Antenatal Depression (AD) in the East Asian countries of Taiwan, China (including Hong Kong and Macau), Japan, and Korea. The main search utilized a Pub med Chinese Electronic Periodical Service (CEPS) literature review using keywords 'AD', and 'Prenatal Depression' with searches for 'Japan, 'Korea, 'Taiwan, 'Hong Kong' and Macau'. The rates of $\mathrm{AD}$ in East Asia appear to be relatively close to those in the Western literature, although certain studies showed slightly decreased rates. Many of the risk factors for $\mathrm{AD}$ were the same in the Eastern and Western literature. These risk factors included demographic factors such as younger age, smoking, low education and income, and unemployment. Other risk factors were physical symptoms such as menstrual pains and nausea. Finally, psychological factors such as a poor response to the pregnancy, poor spousal support, and poor family support were associated with $\mathrm{AD}$. With regard to treatment, there were no studies examining the administration of psychotropic medications for $\mathrm{AD}$. The literature from East Asia both confirmed many Western findings and made unique contributions to the literature on $\mathrm{AD}$. The treatment of $\mathrm{AD}$ in East Asia appears to be an entity which, despite its morbidity, has not been adequately studied.

Psychiatry Investig 2012;9:111-118

Key Words Antenatal depression, Women's health, Cross-cultural.

\section{INTRODUCTION}

Mood disorders are increasingly recognized as a major public health burden across the globe. Unipolar depression, for instance, has been found to be the eighth leading cause of morbidity in low-income countries and the primary cause of morbidity in middle-and high-income countries. ${ }^{1}$ This finding underscores the importance of investigating factors which contribute to and exacerbate depression around the world.

Most westerns studies suggest that women constitute twothirds of the patients suffering from depressive disorders. ${ }^{2}$ Sex differences in the rates of depression often begin to appear in adolescence, a time of major change in the neuroendocrine reproductive axis. ${ }^{3}$ It has thus been hypothesized that fluctuations in ovarian steroids during specific phases of the reproductive cycle play a significant role in women's in-

Received: April 28, 2011 Revised: June 29, 2011

Accepted: March 12, 2012 Available online: May 22, 2012

$\triangle$ Correspondence: Mei-Chun Hsiao, MD

Department of Psychiatry, Chang-Gung Hospital and Chang-Gung University School of Medicine, 5 Fu-Shin Street, Kweishan 333, Taoyuan, Taiwan

Tel: +886-3-3281200, ext.2439, Fax: +886-3-3277859

E-mail: norase@cgmh.org.tw

(a) This is an Open Access article distributed under the terms of the Creative Commons Attribution Non-Commercial License (http://creativecommons.org/licenses/bync/3.0) which permits unrestricted non-commercial use, distribution, and reproduction in any medium, provided the original work is properly cited. creased vulnerability to depression. One such period is during pregnancy. Although at one point in time it was thought that pregnancy was preventative regarding depression, current research indicates that this is not the case. ${ }^{4} \mathrm{~A}$ recent meta-analysis ${ }^{5}$ of 21 studies on depression during pregnancy $(\mathrm{AD})$, for instance, indicated that the prevalence of $\mathrm{AD}$ was approximately $10.7 \%$, ranging from $7.4 \%$ in the first trimester to $12.8 \%$ in the second trimester. The rate of $\mathrm{AD}$ in individual studies, however, was as high as $24 \%$.

In addition to the maternal morbidity from depression itself, antenatal depression is associated with an increased risk of underutilization of prenatal care, ${ }^{6}$ increased obstetric complications and preterm birth, ${ }^{7}$ and post-partum depression. ${ }^{8}$ Previous research has elucidated numerous risk factors for $\mathrm{AD}$. These risk factors include antenatal anxiety, life stress, previous history of depression, lack of social support, unexpected pregnancy, Medicaid insurance status, domestic violence, lower income, lower education, smoking, single status, and poor relationship quality. Life stress, lack of social support, and domestic violence continued to demonstrate a significant association after multivariate analyses. ${ }^{9}$ As noted above, $\mathrm{AD}$ itself is a risk factor for Postpartum Depression (PPD), a disorder with significant morbidity and even mortality. ${ }^{8}$ There has also recently been increasing interest in the West in examining the effects of antenatal stress and depres- 
sion on birth outcomes and future child development. Brand and Brennan ${ }^{10}$ reviewed the literature on this subject and concluded that antenatal depression can have effects on later cognitive development and that $\mathrm{AD}$ is associated with ADHD and other maladaptive behavior in the child. AD has continued to garner increased attention in recent years. In 2003 , for example, it was noted that approximately $13 \%$ of women in the United States took an antidepressant at some point during their pregnancy. ${ }^{11}$

The above research has largely been conducted with Western populations. East Asia, often considered to be more family oriented than the West, would be hypothesized to place a great value on any research which increases the fidelity of the family unit. Further, given that women have always provided the majority of family and child care and are now also being asked to shoulder a larger role in other aspects of modern society, it would be expected that the countries of East Asia would desire to optimize the mental health of women living in those countries. Indeed, in East Asia there has been increasing interest in examining the changes in mood present during women's hormonal fluctuations. In both the West and in East Asia, there has been considerably more work done on PPD when compared to AD. An examination of the PPD literature in East Asia has already been reviewed quite recently and sufficiently. ${ }^{12}$ To this author's knowledge, there has been no similar assessment of the research literature regarding $\mathrm{AD}$ in East Asia. The purpose of this current review was thus to fill in this gap by reviewing studies examining AD in East Asia. East Asia was defined as including the countries of China (including Hong Kong and Macau), Japan, Taiwan, and South Korea. This definition of East Asia was utilized because these countries share a common culture rooted in ancient Buddhist, Taoist, and Confucian values.

\section{METHODS}

The databases Medline and Chinese Electronic Periodical Service (CEPS) were systematically reviewed using the following keywords: 'Antenatal Depression' and 'Asia. Additionally, one review article was utilized which summarized the literature on reproductive disorders in the Peoples Republic of China published in Mainland Chinese Journals. ${ }^{13}$ This methodology found 45 articles on Pub med, while the CEPS search found another three articles. Twenty-nine articles were excluded because they were not related to East Asia or because they examined cross-cultural psychometrics testing parameters. Three additional Chinese studies were found in the mainland Chinese review article. ${ }^{13}$

\section{RESULTS}

\section{Rates of $\mathrm{AD}$ in East Asia}

Chinese researchers have published numerous studies examining the rates of depression during pregnancy. Depending on the study, these rates varied from $5.5 \%$ to $23.1 \% .^{13,14}$ Studies from other East Asian countries also seemed to reach varied conclusions regarding the rate of AD. Using the Hospital Anxiety and Depression Rating Scale (HAD), Lee et al. ${ }^{15}$ found that the rates of $\mathrm{AD}$ ranged from $18.9 \%$ in the second trimester to $22.1 \%$ in the first trimester in a cohort of 357 women in Hong Kong. Though the studies authors explain why they used the Hospital Anxiety and Depression Scale, it is hard to compare their results with studies that use more common measures of depession, such as the Beck Depression Inventory (BDI). In Taiwan, Hsu and Chen ${ }^{16}$ published in the Chinese language literature that, in 150 Taiwanese pregnant women, $20 \%$ of subjects were depressed during the third trimester of pregnancy. This study utilized the Edinburgh Perinatal Depression Scale (EPDS) to assess depression. On the other hand, Kitamura et al. ${ }^{17}$ conducted a study in which midwives used an ad hoc structured interview to diagnose AD in 290 pregnant Japanese women. Using this method, Kitamura found that $5.6 \%$ of the women had AD, a smaller rate than was found in the Chinese literature. Qiao et al. ${ }^{18}$ also found a low rate of $\mathrm{AD}, 4.8 \%$, in his study of 527 pregnant women. In this study, however, $\mathrm{AD}$ was assessed using a self-designed questionnaire for hospital anxiety and depression. Since this instrument is not validated, it is difficult to compare these findings to those of the other studies mentioned regarding rates of $\mathrm{AD}$. A summary of these studies can be seen in Table 1 .

\section{Characteristics associated with $\mathrm{AD}$ in East Asia}

One of the earliest studies to examine AD in East Asia investigated early loss of the woman's parents (death of parent before age 16 or separation for 12 months or longer) as a risk factor for $\mathrm{AD}$ among 120 pregnant women in Japan. ${ }^{19}$ Women with $\mathrm{AD}$, as diagnosed using the Schedule for Affective Disorders and Schizophrenia (SADS), were significantly more likely to have experienced loss of either parent than those women without AD. Kitamura's later research ${ }^{20}$ exam- $^{-}$ ined AD in 1329 women attending an antenatal clinic. Those women scoring high on the Zung Depression Scale (Zung-SDS) were compared with those women with low scores. Women with high scores were more likely to be characterized by the following factors: first delivery; more nausea, vomiting, and anorexia; more menstrual pains and premenstrual irritability; early paternal loss; lower maternal care and higher paternal overprotection; higher public self-consciousness score; 
Table 1. Rates of Antenatal Depression (AD) in selected East Asian countries

\begin{tabular}{|c|c|c|c|c|}
\hline Study & Country & Sample size & Measures used to assess $\mathrm{AD}$ & Prevalence of $\mathrm{AD}$ \\
\hline Lee et al., 2007 & Hong Kong (PRC) & 357 & $\mathrm{HAD}$ & $18.1 \%$ (first semester)-22.1\% (second semester) \\
\hline Hsu and Chen, 2008 & Taiwan & 150 & EPDS & $20 \%$ (first trimester) \\
\hline Kitamura et al., 2006 & Japan & 290 & Structured interview* & $5.6 \%$ \\
\hline Qiao et al., 2009 & China & 527 & Anxiety and depression scale ${ }^{\dagger}$ & $4.8 \%$ \\
\hline
\end{tabular}

*Ad hoc interview conducted by midwives which attempted to summarize major psychiatric diagnoses occurring during childbirth, ${ }^{\dagger}$ Study's own self-devised scale. HAD: Hospital Anxiety and Depression Scale, EPDS: Edinburgh Perinatal Depression

more smoking and use of medication in pregnancy; unwanted pregnancy; negative psychological response to the pregnancy by the woman and husband; poor intimacy in the relationship; and having remarried. The findings regarding the relationship between $\mathrm{AD}$ and nausea and vomiting was supported by Chou's findings in Taiwan. ${ }^{21}$ In this study, Chou examined the records of 113 women receiving prenatal care. Chou also found that $\mathrm{AD}$ was associated with increased fatigue during pregnancy. Honio et al. ${ }^{22}$ examined the important relationship between $\mathrm{AD}$ in 216 women and later mother/infant attachment. This study found that there was no direct association between $\mathrm{AD}$, as assessed by the Z-SDS, and maternal-fetal attachment before fetal movement was perceived. Kitamura et al. ${ }^{17}$ found that women with antenatal depression were characterized by young age and negative attitude towards the current pregnancy. Additionally, antenatal depression was a major risk factor for PPD. Qiu's work ${ }^{23}$ echoed the results from some of Kitamura's earlier studies, showing that in 373 pregnant women poor marital relations, lack of family support, fear of being pregnant and negative life events during pregnancy were significantly associated with $\mathrm{AD}$. This study also found that low education, low income, and unemployment were risk factors for AD. This study utilized the EPDS and the BDI to assess depressive symptoms. Shi et al. ${ }^{14}$ utilized the EPDS and found that having a poor relationship with one's mothers-in-law and spouse was significantly associated with $\mathrm{AD}$ in 600 Chinese women. In this study, older age when pregnant was a risk factor for AD. Lee et al. ${ }^{15}$ found that, after logistic regression analyses, a history of alcohol abuse was associated with an increased risk of $\mathrm{AD}$ during the first and third trimester in 357 pregnant women. Hsu and Chen ${ }^{17}$ found that the best predictors of depression during pregnancy were total stress, lack of social support, and unemployment. In Taiwan, Tseng et al. ${ }^{24}$ examined the narratives of 12 Taiwanese women scoring above 15 on the EPDS. This group found that unbalanced commitment to motherhood was the primary theme in these 12 women. Factors which seemed to contribute to this ambivalence were grouped into 5 subthemes: multiple conflicting roles, lack of social support, dissatisfaction with one's body image, future uncertainty, and emotional instability. Qiao et al. ${ }^{18}$ indicated that younger age when pregnant was a risk factor for depression. Lee et al. ${ }^{25}$ contributed an interesting study to the $\mathrm{AD}$ literature, investigating the relationship between traditional Chinese antenatal taboos during pregnancy and depression. Lee found that, after in depth interviews with 60 women, a significant number of these women resented the loss of freedom imposed by these antenatal taboos, and that disputes with family regarding taboos were associated with significantly higher rates of $\mathrm{AD}$. In this study, the depression was measured using the BDI. Another recent unique study studied the relationship between pre-natal and post-natal emotional symptoms. In this study, Ngai and colleagues ${ }^{26}$ found that $\mathrm{AD}$ was negatively associated with maternal role competence and satisfaction during the post-partum period in 184 first-time pregnant women in Hong Kong. In this study, AD was assessed using the EPDS. A summary of these studies can be seen in Table 2 .

\section{Treatment of AD in East Asia}

In one of the first studies published in the Chinese literature, Chen et al. ${ }^{27}$ provided group therapy to 216 women from pregnancy until postpartum. The results showed that the intervention group had a significantly lower rate of depressive symptoms at each assessment point, and the children of women in the intervention group showed significantly better performance on intelligence and behavior measures. Of note, however, AD was not assessed in this study. On the other hand, another Chinese group ${ }^{28}$ provided an educational program to women with antenatal depression, and failed to show a significant decrease in depression at days 3 and 42 after the educational program, and at 3 months post-partum. The most important problem with these two studies is that the description of methods of the psychological intervention is vague. All the studies, for example, lacked a description of structured content for the intervention and the qualification of clinicians providing these interventions. Recently, other innovative methods of preventing and treating $\mathrm{AD}$ have been investigated. Chang et al. ${ }^{29}$ randomly assigned 236 pregnant women to music therapy and control groups. They noted that women in the music therapy group showed a significant decrease in EPDS after two weeks. Su et al. ${ }^{30}$ randomized 36 
Table 2. Characteristics of women with Antenatal Depression (AD) in selected East Asian countries

\begin{tabular}{|c|c|c|c|c|}
\hline Study & Country & Sample size & $\begin{array}{l}\text { Measures used to } \\
\text { assess } \mathrm{AD}\end{array}$ & Characteristic identified \\
\hline Kitamura et al., 1994 & Japan & 120 & SADS & $\begin{array}{l}\text { Increased incidence of } \mathrm{AD} \text { in women with early loss } \\
\text { of parents* }\end{array}$ \\
\hline Kitamura et al., 1996 & Japan & 1,329 & Zung-SDS & $\begin{array}{l}\text { AD associated with first delivery, more nausea, vomiting, and } \\
\text { anorexia, more menstrual pains and irritability, early paternal } \\
\text { loss, lower maternal care, higher paternal overprotection, } \\
\text { higher public self-consciousness, more smoking, increased use } \\
\text { of use of medications during pregnancy, unwanted pregnancy, } \\
\text { unwanted pregnancy, negative psychological response to the } \\
\text { pregnancy, poor intimacy between couple, having remarried }\end{array}$ \\
\hline Chou et al., 2003 & Taiwan & 113 & Questionnaire & $\mathrm{AD}$ associated with increased nausea, vomiting, and fatigue \\
\hline Honio et al., 2003 & Japan & 216 & Zung-SDS & $\begin{array}{l}\text { AD not associated with disrupted maternal/fetal attachment } \\
\text { before fetal movement perceived }\end{array}$ \\
\hline Kitamura et al., 2006 & Japan & 290 & Structured interview ${ }^{\dagger}$ & $\begin{array}{l}\mathrm{AD} \text { associated with young age, negative attitude towards } \\
\text { pregnancy, and PPD }\end{array}$ \\
\hline Qiu and Wang, 2006 & China & 373 & EPDS, BDI & $\begin{array}{l}\mathrm{AD} \text { associated with poor marital relations, lack of family support, } \\
\text { fear of being pregnancy, and negative life events during } \\
\text { pregnancy, low education, low income, unemployment }\end{array}$ \\
\hline Shi et al., 2007 & China & 600 & EPDS & $\begin{array}{l}\text { AD associated with older age, poor relationship with one's } \\
\text { mother-in-law and spouse }\end{array}$ \\
\hline Lee et al., 2007 & Hong Kong & 357 & $\mathrm{HAD}$ & $\begin{array}{l}\text { Increased risk of } \mathrm{AD} \text { during first and third trimester } \\
\text { associated with alcohol abuse } \mathrm{f}^{\ddagger}\end{array}$ \\
\hline Hsu and Chen, 2008 & Taiwan & 150 & EPDS & $\begin{array}{l}\mathrm{AD} \text { associated with total stress, lack of social support, } \\
\text { and unemployment }\end{array}$ \\
\hline Tseng et al., 2009 & Taiwan & 12 & $\begin{array}{l}\text { EPDS, } \\
\text { Narrative reports } \\
\text { of AD experience }\end{array}$ & $\begin{array}{l}\text { AD associated with unbalanced commitment to motherhood } \\
\text { with the following subthemes: multiple conflicting roles, lack } \\
\text { of social support, dissatisfaction with one's body image, } \\
\text { future uncertainty, and emotional instability }\end{array}$ \\
\hline Qiao et al., 2009 & China & 527 & $\begin{array}{c}\text { Anxiety and } \\
\text { depression scale§ }\end{array}$ & $\mathrm{AD}$ associated with younger age when pregnant \\
\hline Lee et al., 2009 & Hong Kong & 60 & BDI & $\begin{array}{l}\mathrm{AD} \text { associates with disputed with family regarding following } \\
\text { traditional Chinese antenatal taboos }\end{array}$ \\
\hline Ngai et al., 2010 & Hong Kong & 184 & EPDS & $\begin{array}{l}\mathrm{AD} \text { associated with poor maternal role competence } \\
\text { and satisfaction at } 6 \text { weeks post-partum }\end{array}$ \\
\hline
\end{tabular}

*Defined as death of parent before age 16 or separation for 12 months or longer, ${ }^{\dagger}$ Ad hoc interview conducted by midwives which attempted to summarize major psychiatric diagnoses occurring during childbirth, ${ }^{\ddagger}$ Results after logistic regression analyses, §Study’s own self-devised scale. SADS: Schedule for Affective Disorders and Schizophrenia, Zung-SDS: Zung Depression Scale, PPD: Post-partum Depression, EPDS: Edinburgh Perinatal Depression, BDI: Beck Depression Inventory, HAD: Hospital Anxiety and Depression Scale

women with AD to Omega-3 Polyunsaturated Fatty Acid (Omega-3 FA) supplementation (3.4 grams/day) vs. placebo for 8 weeks. Patients receiving the active treatment had significantly lowered Hamilton Rating Scale for Depression (HAM-D) scores and significantly higher rates of response and remission at weeks 6 and 8. In Korea, Cho et al. ${ }^{31}$ utilized a questionnaire format with 1,314 pregnant women. This group found a trend for Folic Acid (FA) and Multivitamins (MVA) protecting against $\mathrm{AD}$, but the relationship was not statistically significant. Finally, Zhang and $\mathrm{Hu}^{32}$ most recently presented a case study of 3 pregnant women who were successfully treated for AD using Repetitive Transcranial Magnetic Simulation (rTMS). In this case report, however, the authors do not make clear how they assessed improvement in $\mathrm{AD}$.

It is notable that only 5 studies could be found examining $\mathrm{AD}$ in the East Asian literature. It is just as significant that none of these studied utilized psychotropic medications, 
Table 3. Treatment of Antenatal Depression (AD) in selected East Asian countries

\begin{tabular}{|c|c|c|c|c|c|}
\hline Study & Country & Sample size & $\begin{array}{l}\text { Measures used } \\
\text { to assess } \mathrm{AD}\end{array}$ & Treatment & Outcome \\
\hline Chen et al., 2004 & China & 216 & * & Group therapy & Lower rate of depressive symptoms \\
\hline Tang et al., 2009 & China & $\dagger$ & $\ddagger$ & Psychoeducation & $\begin{array}{l}\text { No lower rate of depressive symptoms } \\
\text { at days } 3 \text { and } 42 \text { after intervention } \\
\text { completion }\end{array}$ \\
\hline Chang et al., 2008 & Taiwan & 236 & EPDS & Music therapy & $\begin{array}{l}\text { Significant decrease in depressive } \\
\text { symptoms compared to control group }\end{array}$ \\
\hline Su et al., 2008 & Taiwan & 36 & HAM-D, EPDS, BDI & $\begin{array}{l}3.4 \mathrm{~g} / \text { day omega-3 } \\
\text { polyunsaturated } \\
\text { fatty acids }\end{array}$ & $\begin{array}{l}\text { Lower HAM-D scores and higher } \\
\text { response and remission rate in active } \\
\text { vs. control group after } 6 \text { and } 8 \text { weeks }\end{array}$ \\
\hline Cho et al., 2008 & Korea & 1,314 & $\begin{array}{l}\text { Depression } \\
\text { questionnaire }\end{array}$ & $\begin{array}{c}\text { Prenatal vitamins } \\
\text { containing Folic Acid }\end{array}$ & $\begin{array}{l}\text { Trend for decrease in } \mathrm{AD} \text { when taking } \\
\text { Prenatal Vitamins containing Folic } \\
\text { Acid, but relationship not statistically } \\
\text { significant }\end{array}$ \\
\hline Zhang and $\mathrm{Hu}, 2009$ & China & 3 & $\S$ & rTMS & Decreased $\mathrm{AD}$ \\
\hline
\end{tabular}

*Unclear which measure used to assess $\mathrm{AD}$, ${ }^{+}$Unclear number of participants, $\neq$Unclear which measure used to assess AD, §Unclear which measure used to assess AD. EPDS: Edinburgh Perinatal Depression, HAM-D: Hamilton Rating Scale for Depression, BDI: Beck Depression Inventory, rTMS: Repetitive Transcranial Magnetic Stimulation

which are the standard of care treatments for $\mathrm{AD}^{6}$ once it has been decided that the patient's $\mathrm{AD}$ needs intervention. A summary of these studies can be seen in Table 3.

\section{DISCUSSION}

The literature examining AD in East Asia has both confirmed certain Western results and added to the body of knowledge regarding $\mathrm{AD}$. The incidence of depression during pregnancy appears to be roughly equal in East Asia and the West, although some studies found a lower incidence of $\mathrm{AD}$ in East Asia. The Asian studies which found lower rates of $\mathrm{AD}$, however, a difference in methodology might explain the different rates of $\mathrm{AD}$ in East Asia and the West.

Lack of social support, single status, and poor relationship quality were all associated with $\mathrm{AD}$ in both Western and Eastern populations. Kitamura et al. ${ }^{19}$ further noted bereavement was a risk factor for $\mathrm{AD}$. Other predictors of $\mathrm{AD}$ in the East Asian literature included poor marital relations, family conflict (particularly with the mother-in-law), and lack of family support. Taken together, it is clear that family dynamics and family support during pregnancy is one of the most crucial factors mediating AD. The literature in East Asia indicates that this family support might be even more important in East Asian populations than in their Western counterparts. One of the most important relationships which exist in the East Asian family is between a daughter and her mother-in-law. Chinese culture emphasizes the concept that the mother-in-law/daughter-in-law relationship is as close as the original mother-daughter relationship. ${ }^{33}$ There is ample
Chinese literature which explores the phenomena of motherin-law/daughter-in-law conflict, ${ }^{34}$ and the mother-in-law's role in affecting their daughter-in-law's depressive symptoms $\mathrm{s}^{35}$ when she is not pregnanct. This review certainly supports the notion that the mother-in-law's role is just as crucial, if not more so, during her daugher-in-law's pregnancy.

In both the East and Western literature unwanted pregnancy was a risk factor for $\mathrm{AD}$. Of significant concern is the fact that planned (and thus desired) pregnancies are more likely to have a good outcome for both the mother and the baby. ${ }^{36}$ Moreover, if a pregnancy is unplanned, there is a greater chance that the mother may be using medications or drugs early in the pregnancy which might affect the developing baby. ${ }^{37}$ Thus, it is important that all countries have mechanisms in place designed to help prevent unplanned or unwanted pregnancies and to maximally assist women with such pregnancies. Obsetricians and Gynecologists have a large role to play in preventing unplanned and unwanted pregnacy by helping ensure adequte use of, and adherence to, contraception. ${ }^{38}$ Additionally, other entities can have a positive role in preventing and caring for unintended or unwanted pregnancies. These services can vary from speciality advice clinics $^{39}$ to comprehensive education websites which women can contact for support and education. ${ }^{40}$

Younger women in East Asia appear to have a greater risk of developing $\mathrm{AD}$. This is in agreement with the Western literature. ${ }^{8}$ Younger women may have a greater number of life stressors which make it difficult to care for herself during her pregnancy. However, one East Asian study ${ }^{14}$ indicated that older age was actually a risk factor for $\mathrm{AD}$. In the West, a cer- 
tain stigma has developed when a woman is pregnant when she is young. ${ }^{8}$ Such a woman is often considered to be less well educated, and more likely to be a single mother. It is possible that, since East Asia is often considered to be more traditional than the West, women having babies when they are young face less this aforementioned stigma.

Factors relating to life stress were also shown to be important in both the Eastern and Western literature. The East Asian literature, for example, discussed multiple conflicting roles and negative life events as being important in predicting $\mathrm{AD}$. Smoking and substance abuse during pregnancy was also risk factors for $\mathrm{AD}$ in both the Eastern and Western literature. ${ }^{41}$ Again, the causality of this relationship is difficult to determine. Given that most women know that smoking/ substance use is bad for the unborn fetus, it is possible that the women who do not give up smoking and continue to abuse substances are under a significant amount of life stress (a risk factor for depression), or that they are already depressed. On the other hand, use of these substances themselves may predispose the woman to developing $\mathrm{AD}$. In both the East and West, a history of other reproductive mood disorders (Premenstrual Dysphoric Disorder and PPD) predicted AD. ${ }^{6}$ Since each of these disorders likely shares a common sensitivity to hormonal fluctuation, this finding is not surprising.

Although the studies examining many aspects of $\mathrm{AD}$ in East Asia are notable, the research regarding treatment of $\mathrm{AD}$ in East Asia has room for further growth. Studies which examined psychotherapeutic treatment strategies for AD were all conducted in China and did not include a detailed discussion of the intervention strategies. Taiwan did produce interesting studies examining alternatives to traditional psychotherapy and medications, such as music therapy ${ }^{29}$ and Omega-3 Fas. ${ }^{30}$ The only somatic treatment for $\mathrm{AD}$ in East Asia was a case study on rTMS in China. ${ }^{32}$ Notably, there were NO studies examining pharmacologic antidepressants in the treatment of AD. Pregnancy is clearly understood all around the world as being incredibly sacred and important. It is likely that, in some countries in East Asia, it is considered better for the health of the baby to minimize any interventions for the mother, since this might put the baby at risk. The literature regarding $\mathrm{AD}$ has implicated untreated $\mathrm{AD}$ as leading to fetal growth changes and shorter gestations. Additionally, it has been previously noted that untreated $\mathrm{AD}$ can have adverse effects on cognitive development and possibly IQ. ${ }^{10}$ These negative consequences mean that it is not prudent to ignore $\mathrm{AD}$ and hope that the pregnancy will be unaffected. It is true that the use of SSRIs during pregnancy have been shown to carry their own risks to the pregnancy. ${ }^{12}$ These risks may be one of the reasons why East Asian physicians are more hesi- tant to study and use antidepressants during pregnancy. While this hesitancy is understandable, it would be important to study the risks and benefits of medications during pregnancy in East Asian countries. To facilitate this goal, it would be necessary for most East Asian countries to have 'Teratogen Information Services' with birth registries. Such information services both provide information to pregnant women and their doctors, and survey women regarding the medication use during pregnancy and subsequent birth outcomes. Such services would be important because pregnant Asian women may be taking more of certain medications, or they may be using different medications, as compared to their Western counterparts. Without a further analysis of medication use among pregnant women in East Asia, the Western literature will always have to be the information source for East Asian physicians. The Japanese Teratology Society has developed a Teratogen Information Service, which belongs to the European Network of Teratogen Information Services. Korea has also recently established a Teratogen Information Service. ${ }^{42}$ Continuing the development of such organizations in other East Asian countries would be important in adding to the literature regarding medication exposures during pregnancy. Such development can look to the models present in Japan and Korea. Additionally, the development of Teratogen Information Services can be aided by the model present in North America. This North American information service is The Organization of Teratology Information Specialists, or OTIS. ${ }^{43}$ OTIS is available to answer the questions of pregnant women and their doctors, and it also has a comprehensive website for pregnancy information. Additionally, OTIS conducts important research into the risks of specific drugs during pregnancy and while breast feeding. Having a service similar to the Japanese, Korean, or North American models could likely produce a large number of research papers, since few studies regarding the risks of medications in pregnant Taiwanese, Cantonese, or Chinese women have been published.

East Asia is ideally placed to contribute to the literature on psychotherapy during pregnancy since psychotropic medications are less used during pregnancy. Such research could examine whether Interpersonal Therapy or Cognitive Behavioral Therapy (two of the most utilized methods of psychotherapy for $\mathrm{AD}$ ) can be helpful in the treatment of $\mathrm{AD}$ in East Asia. The East Asian literature has made some pioneering efforts, investigating newer types of therapy for $\mathrm{AD}$, such as the rTMS discussed above. Further, there are treatments for psychiatric disorders which originated in East Asia and have just begun to be studied in the West. Acupuncture, for instance, has recently been shown to be helpful for $\mathrm{AD}$ in the West. ${ }^{44}$ East Asian researchers can certainly further this re- 
search with their own investigation of acupuncture and other indigenous East Asian methods of healing. Su's work on Omega-3 FA's ${ }^{30}$ is certainly promising and exciting, since this treatment for $\mathrm{AD}$ is cheap and has so few side effects.

Taken as a whole, the East Asian literature has contributed in unique ways to the study of $\mathrm{AD}$. Research regarding the treatment of $\mathrm{AD}$ in East Asia, however, appear to be sparse. This is an entity which should, and likely will, be examined more closely by East Asian researchers in the years to come.

\section{Acknowledgments}

We declare no conflicts of interest. The author would like to thank all members of the women's mental health program at Chang Gung Hospital.

\section{REFERENCES}

1. World Health Organization. Global Burden of Disease: 2004 Update. Geneva: WHO Press; 2008.

2. Kessler RC, McGonagle KA, Swartz M, Blazer DG, Nelson CB. Sex and depression in the National Comorbidity Survey. I: Lifetime prevalence, chronicity and recurrence. J Affect Disord 1993;29:85-96.

3. Kessler RC, McGonagle KA, Zhao S, Nelson CB, Hughes M, Eshleman $\mathrm{S}$, et al. Lifetime and 12-month prevalence of DSM-III-R psychiatric disorders in the United States: Results from the National Comorbidity Survey. Arch Gen Psychiatry 1994;51:8-19.

4. Spinelli MG. Interpersonal psychotherapy for depressed antepartum women: a pilot study. Am J Psychiatry 1997;154:1028-1030.

5. Bennet HA, Einarson A, Taddio A, Koren G, Einarson TR. Prevalence of depression during pregnancy: systematic review. Obstet Gynecol 2004;103:698-709.

6. Marcus SM. Depression during pregnancy: rates, risks and consequences--Motherisk Update 2008. Can J Clin Pharmacol 2009;16:e15e22.

7. Wisner KL, Sit DK, Hanusa BH, Moses-Kolko EL, Bogen DL, Hunker DF, et al. Major depression and antidepressant treatment: impact on pregnancy and neonatal outcomes. Am J Psychiatry 2009;166:557-566.

8. Robertons E, Grace S, Wallington T, Stewart DE. Antenatal risk factors for postpaartum depression: a synthesis of recent literature. Gen Hosp Psychiatry 2004;26:293-295.

9. Lancaster CA, Gold KJ, Flynn HA, Yoo H, Marcus SM, Davis MM. Risk factors for depressive symptoms during pregnancy: a systematic review. Am J Obst Gynecol 2010;202:5-14.

10. Brand SR, Brennan PA. Impact of antenatal and postpartum mental illness: how are the children? Clin Obstet Gynecol 2009;52:441-455.

11. Cooper WO, Willy ME, Pont SJ, Ray WA. Increasing use of antidepressants in pregnancy. Am J Obstet Gynecol 2007;196:544.e1-e5.

12. Klainin P, Arthur DG. Postpartum depression in Asian cultures: a literature review. Int J Nurs Stud 2009;46:1355-1373.

13. Qiu JY, Xiao ZP. Reproductive-related depression in women: a review of two decades of research in China. Asia-Pac Psychiatry 2010;2:19-25.

14. Shi SX, Tang YF, Cheng LN, Su QF, Qi K, Yang YZ. An investigation of the prevalence of anxiety or depression and related risk factors in women during pregnancy and postpartun. Chin Ment Health J 2007;21: 254-258.

15. Lee AM, Lam SK, Sze Mun Lau SM, Chong CS, Chui HW, Fong DY. Prevalence, course, and risk factors for antenatal anxiety and depression. Obstet Gynecol 2007;110:1102-1112.

16. Hsu $\mathrm{CM}$, Chen $\mathrm{CH}$. The prevalence and predictors of prenatal depression. J Evid Based Nurs 2008;4:149-156.

17. Kitamura T, Yoshida K, Okano T, Kinoshita K, Hayashi M, Toyoda N, et al. Multicentre prospective study of perinatal depression in Japan: Incidence and correlates of antenatal depression and postnatal depres- sion. Arch Womens Ment Health 2006;9:121-130.

18. Qiao YX, Wang J, Li J, Ablat A. The prevalence and related risk factors of anxiety and depression symptoms among Chinese pregnant women in Shanghai. Aust N Z J Psychiatry 2009;49:185-190.

19. Kitamura T, Toda MA, Shima S, Sugawara M. Early loss of parents and early rearing experience among women with antenatal depression. J Psychosom Obstet Gynecol 1994;15:133-139.

20. Kitamura T, Sugawara M, Sugawara K, Toda MA, Shima S. Psychosocial study of depression in early pregnancy. Br J Psychiatry 1996;168: 732-738.

21. Chou FH, Lin LL, Cooney At, Walker LO, Riggs MW. Psychosocial factors related to nausea, vomiting, and fatigue in early pregnancy. J Nurs Scholarsh 2003;35:119-125.

22. Honjo S, Arai S, Kaneko H, Ujiie T, Murase S, Sechiyama H, et al. Antenatal depression and maternal-fetal attachment. Psychopathology 2003;36:304-311.

23. Qiu JY, Wang ZC. Detecting depressive symptoms and risk factors in women in mid to late pregnancy. Chin Ment Health J 2006;20:469-471.

24. Tseng YF, Hsu CM, Liu YH, Chen CH. The experience of prenatal depression among Taiwanese Women. J Adv Nurs 2008;64:495-503.

25. Lee DT, Ngai IS, Ng MM, Lok IH, Yip AS, Chung TK. Antenatal taboos among Chinese women in Hong Kong. Midwifery 2009;25:104-113.

26. Ngai FW, Wai-Chi Chan S, Ip WY. Predictors and correlates of maternal role competence and satsifaction. Nurs Res 2010;59:185-193.

27. Chen SX, Wen CL, Shang YH. The psychological intervention to postpartum depression and its influence to infants psychological development. Chin Ment Health J 2004;18:254-258.

28. Tang YF, Shi SX, Lu W, Chen Y, Wang QQ, Zhu YY. Prenatal psychological prevention trial on postpartum anxiety and depression. Chin Ment Health J 2009;23:83-89.

29. Chang MY, Chen CH, Huang KF. Effects of music therapy on psychological health of women during pregnancy. J Clin Nurs 2008;17:25802587.

30. Su KP, Huang SY, Chiu TH, Huang KC, Huang CL, Chang HC, et al. Omega-3 fatty acis for major depressive disorder during pregnancy: results from a randomized, double-blind placebo-controlled trial. J Clin Psychiatry 2008;69:644-651.

31. Cho YJ, Han JY, Choi JS, Ahn HK, Ryu HM, Kim MY, et al. Prenatal multivitamins containing folic acid do not decrease prevalence of depression among pregnant women. J Obstet Gynaecol 2008;28:482-484.

32. Zhang D, Hu Z. RTMS may be a good choice for pregnant women with depression. Arch Womens Ment Health 2009;12:189-190.

33. Hsu SC, Huang LL. Beyond mother-daughter affection: multiple harmonies for mothers and daughters-in-law. Indig Psychol Res Chin Soc 2009;26:35-72.

34. Huang LL, Hsu SC. From superficiality to genuineness: harmonization processes and tranformation mechanisms between mothers- and daughters-in-law. Indig Psychol Res Chin Soc 2006;25:3-45.

35. Huang YH, Yu SH, Lin MF. A depressed woman's views of disease experiences and the relation of mother and daughter-in-law. Formosa J Ment Health 2009;22:27-50.

36. Hellerstedt WL, Pirie PL, Lando HA, Curry SJ, McBride CM, Grothaus LC, et al. Differences in preconceptional and prenatal behaviors in women with intended and unintended pregancy. Am J Pub Health 1998;88:663-666.

37. Kaufman D, Kelly J, Rosenberg L, Anderson TE, Mitchell AA. Recent patterns of medication use in the ambulatory adult population of the United States: the Slone survey. JAMA 2002;287:337-344.

38. Freeman SB. Preventing unplanned pregnancy. The right contraceptive fit can make a difference. Adv Nurs Pract 2005;13:57-59, 61-62, 67.

39. Williams EC, Kirkman RJ, Elstein M. Profile of young people's advice clinic in reproductive health, 1988-93. BMJ 1994;309:786-788.

40. Planned Parenthood Fedaration of America. Available at: http://www. plannedparenthood.org/index.htm. Accessed June 28, 2010.

41. Ryan D, Milis L, Misri N. Depression during pregnancy. Can Fam 
Physician 2005;51:1087-1093.

42. Chambers C. Personal Communication. June 2010.

43. Organization of Teratology Information Specialists. Available at: http:// www.otispregnancy.org/. Accessed June 17, 2010.
44. Manber R, Schnyer RN, Lyell D, Chambers AS, Caughey AB, Druzin $\mathrm{M}$, et al. Acupuncture for depression during pregnancy: a randomized controlled trial. Obstet Gynecol 2010;115:511-520. 